\title{
Batallando con fronteras: estrategias migratorias en tránsito de participantes en caravanas de migrantes
}

\section{Crossing borders: migratory strategies in transit of participants in migrants caravans}

Eduardo Torre Cantalapiedra ${ }^{a^{*}}$ (D) https://orcid.org/0000-0002-4074-3752 Dulce María Mariscal Navaa (i) https://orcid.org/0000-0002-9296-2631

\begin{abstract}
${ }^{a}$ El Colegio de la Frontera Norte, Tijuana, México, correo electrónico: eduardotorrephd@gmail. com,dmariscaln@gmail.com
\end{abstract}

\section{Resumen}

A finales de 2018, varias caravanas de migrantes ingresaron a México con el propósito de llegar a Estados Unidos. Sus integrantes, mayormente del denominado Norte de Centroamérica - particularmente de Honduras- huían de la pobreza y la violencia en sus países de origen. Este trabajo analiza las estrategias migratorias en tránsito de los participantes en tales caravanas para vencer los obstáculos en su camino hacia el Norte, especialmente en su paso por México. Para este propósito se realizaron 47 entrevistas a personas centroamericanas en albergues temporales en la ciudad de Tijuana, Baja California. Concluimos que la participación en tales caravanas constituyó una nueva estrategia migratoria en tránsito que pone de manifiesto, a la vez que desafía, la capacidad de agencia de los migrantes para el logro de sus objetivos migratorios.

Palabras clave: migración internacional, migrantes centroamericanos, estrategias migratorias, migración en tránsito, México.

\begin{abstract}
At the end of 2018, several migrant caravans entered to Mexico with the purpose of reaching to United States. Their members, mostly from the so-called North of Central America - especially from Honduras- were fleeing poverty and violence in their countries of origin. This work analyzes the migratory strategies in transit of the participants in such caravans to overcome the obstacles on their way to the North, especially through Mexico. For this purpose, 47 interviews were conducted to Central American people in temporary shelters in the city of Tijuana, Baja California. We conclude that participation in
\end{abstract}

Esta obra está protegida bajo una Licencia Creative Commons Atribución-NoComercial 4.0 Internacional.
CÓMO CITAR: Torre, E. \& Mariscal, D. M. (2020). Batallando con fronteras: estrategias migratorias en tránsito de participantes en caravanas de migrantes. [Crossing borders: migratory strategies in transit of participants in migrants caravans]. Estudios Fronterizos, 21, e047. https://doi.org/10.21670/ref.2005047 
such caravans constituted a new migratory strategy in transit that reveals, as well as challenges, the agency's capacity of migrants to achieve their migratory objectives.

Keywords: international migration, Central American migrants, migratory strategies, transit migration, Mexico.

\section{Introducción}

El 13 de octubre de 2018, un grupo de migrantes ${ }^{1}$ originarios de Honduras, que pronto fue denominado por los medios de comunicación como "caravana migrante", ${ }^{2}$ partió con el objetivo de cruzar juntos Centroamérica y México para llegar a Estados Unidos, algunos con la intención de permanecer en territorio mexicano o bien marchaban sin prever su destino. El lema de esta primera caravana ilustra elocuentemente las principales fuerzas que les compelieron a salir de Honduras: "no nos vamos porque queremos, nos expulsa la violencia y la pobreza" (citado en Meléndez, 2018). A esta primera marcha pronto le siguieron otras.

La difusión de estas caravanas por redes sociales en Internet -Facebook y WhatsApp—, los medios de comunicación de masas —especialmente la televisión-y las conversaciones cotidianas, coadyuvaron a que un creciente número de personas se incorporaran a ellas, en su mayoría procedentes de países del denominado Norte de Centroamérica (NCA), entre las que destacan las originarias de Honduras, y en menor medida, de El Salvador y Guatemala. ${ }^{3}$ Asimismo, a medida que proseguían su incesante trayecto hacia el Norte, se integraron otros migrantes que habían iniciado su camino con anterioridad.

Según cifras oficiales, más de nueve mil migrantes centroamericanos se encontraban en territorio mexicano participando en las caravanas en diciembre de 2018 (Jiménez \& Canchola, 2018). La mayoría recorrió cientos de kilómetros atravesando el territorio mexicano en un escenario donde las "reglas del juego" del tránsito habían sido alteradas por y para tales marchas. Lo que se tradujo en nuevas posibilidades y desafíos para los migrantes que recorren el territorio mexicano.

Este trabajo analiza las estrategias migratorias en tránsito de los participantes en las caravanas para vencer los obstáculos en su camino hacia Estados Unidos,

\footnotetext{
${ }^{1}$ En este trabajo al utilizar el término migrantes incluimos a todos los que se movilizaron con independencia del motivo de la emigración y el grado de voluntariedad en la decisión de emigrar. Por tanto, incluimos a quienes se definen como refugiados: "personas que están fuera de su país de origen debido a un temor de persecución, a un conflicto, violencia u otras circunstancias que perturben gravemente el orden público, y quienes, en consecuencia, requieren 'protección internacional'" (Alto Comisionado de las Naciones Unidas para los Refugiados [ACNUR], 2016), migrantes por razones laborales, migrantes que se desplazan por situaciones de pobreza extrema, migrantes que buscan reunirse con sus familias, entre otros. Asimismo, hay que tener en cuenta que es frecuente que los migrantes centroamericanos respondan a más de un motivo en sus decisiones para movilizarse.

${ }^{2}$ De acuerdo con el Diccionario del Español de México, caravana se define como: "grupo de personas que se reúnen para ir juntos a determinado lugar en vehículos, caballos o a pie" (El Colegio de México [EI Colmex], 2018). En este trabajo se emplean indistintamente los términos caravana y marcha.

${ }^{3}$ Entre ellos, personas que llevaban tiempo planeando salir de sus países de origen y cuyas circunstancias vitales eran insostenibles por la violencia, la pobreza o ambas.
} 
especialmente durante su paso por México. Teniendo como referente el concepto empleado en Silva Hernández (2015), se considera que las estrategias migratorias en tránsito se constituyen por el uso que hacen de ellas los migrantes en tránsito, entendidos como sujetos con cierta capacidad de agencia, de los recursos personales, interpersonales e institucionales que son capaces de desarrollar y emplear, en una secuencia de decisiones y acciones que se despliegan para hacer frente a los obstáculos que se interponen en su camino para alcanzar su destino migratorio.

Los migrantes procedentes del NCA no solo afrontan el cruce de las fronteras entre Guatemala y México y entre México y Estados Unidos, sino que a lo largo del territorio mexicano deben lidiar con la denominada frontera vertical; esta última se compone de los puntos de control desplegados por las autoridades mexicanas y de la presencia de delincuencia organizada que pretende sacar provecho de los migrantes que se movilizan en condiciones y bajo circunstancias que los hacen vulnerables (Yee Quintero \& Torre Cantalapiedra, 2016).

Los análisis respecto a las estrategias de los migrantes y sus familias conforman un nuevo campo de estudio que analiza los diversos procesos migratorios y consideran protagonistas a quienes se movilizan en: origen (Jardón Hernández, 2011); tránsito (Villanueva Domínguez, 2012; Díaz Prieto \& Khuner, 2014; Silva Hernández, 2015; Yee Quintero \& Torre Cantalapiedra, 2016; Yee Quintero, 2017; Parrini Roses \& Flores Pérez, 2018); tránsito y asentamiento (París Pombo, 2017, 2018a); destino (Pedone et al., 2014; Méroné \& Torre Cantalapiedra, 2020), ante la deportación de alguno/s de sus miembros (Peláez \& París, 2016; Rodríguez Gutiérrez \& Torre Cantalapiedra, s. p.), entre otras. Asimismo, esta nueva agenda de investigación considera la recuperación de sus voces una prioridad, y las establece como un contrapunto de las visiones de organismos internacionales y funcionarios públicos que consideran que la planeación y gestión - control- de las migraciones puede llevarse a cabo sin tener en cuenta las pretensiones de los propios migrantes.

Para el logro del objetivo propuesto, este trabajo se divide en tres partes. Primero, se sitúa a las caravanas de migrantes en el contexto de las migraciones desde el NCA y su tránsito por México hacia Estados Unidos. Segundo, se trae a colación la literatura académica sobre migración en tránsito para construir un marco para el análisis compuesto de cinco estrategias: 1. Elección de rutas y de medios de transporte; 2. Acompañamiento; 3. Obtención de algún tipo de documento migratorio; 4. Apoyo en la red asistencial: los albergues; y, 5. Acudir al servicio de coyotaje. Tercero, mediante 47 entrevistas, en las que recuperamos las experiencias migratorias de personas centroamericanas participantes en las caravanas de migrantes llegadas a Tijuana entre noviembre y diciembre de 2018, se analizan las estrategias en tránsito que despliegan los integrantes de dichas caravanas.

\section{Caravanas de migrantes transitando por México en contexto}

Desde la década de 1990, el fenómeno de la migración centroamericana en tránsito por el territorio mexicano, procedente en su mayoría del NCA, se ha caracterizado por: 
1) su gran dimensión cuantitativa y dirección hacia Estados Unidos; 2) el predominio de la situación de irregularidad; y, 3) el haber sufrido incontables abusos y agresiones por grupos criminales y autoridades migratorias (Calva Sánchez et al., 2015; El Colegio de la Frontera Norte [El Colef] et al., 2019).

En las acciones políticas de los sucesivos gobiernos mexicanos, en respuesta a esta realidad migratoria, ha primado el control y la perspectiva de la seguridad nacional, en este sentido el gobierno mexicano ha erigido una frontera vertical oficial — conjunto de medios humanos y materiales desplegados para el control de flujos migratorios a lo largo del territorio mexicano- que pone a los migrantes en riesgo continuo de ser detenidos y deportados por autoridades mexicanas desde cualquier punto del país (Silva Hernández, 2015; Torre Cantalapiedra \& Yee Quintero, 2018). Recientemente, las autoridades mexicanas han incorporado el enfoque de la protección de los derechos humanos de los migrantes extranjeros en tránsito en sus diversos discursos políticos y legales respecto a la migración (Ley de Migración de 2011, comunicados de prensa del Instituto Nacional de Migración [INM], entre otros), pero hay escasa información y análisis sobre la trascendencia práctica de estos cambios.

En cuanto a las últimas tendencias respecto a la migración centroamericana en el territorio mexicano, cabe destacar el repunte de personas huyendo de la pobreza y la violencia en sus países de origen con destino a Estados Unidos —así en 2014, hubo 418000 eventos de tránsito por México, que incluye un auge en la presencia de mujeres, niños y adolescentes (Rodríguez Chávez, 2016). Asimismo, hay que señalar las redes sociales más o menos densas que tienen los migrantes en territorio estadounidense especialmente cuando existen vínculos fuertes: familiares cercanos-, mayores niveles de seguridad y los más altos salarios que pueden lograr en aquel país como tres factores que compelen a los migrantes centroamericanos a elegir Estados Unidos como país de destino; con independencia del motivo que ocasionó la salida de sus países de origen. Esto no es óbice para que un creciente número de migrantes centroamericanos se queden en territorio mexicano, ya sea porque reformularon o desistieron de sus planes de alcanzar Estados Unidos o porque escogieron México como "destino final" (El Colef et al., 2019; Torre Cantalapiedra, 2020).

En cualquier caso, pese a las tendencias alcistas, hasta fechas recientes, el volumen de inmigrantes centroamericanos en México se ha mantenido en cifras relativamente reducidas (Giorguli-Saucedo et al., 2018) y siempre existe la posibilidad de que los migrantes que permanecen, más tarde o temprano, aprovechen ciertas oportunidades para "reanudar" su camino hacia el Norte o retornen a sus países de origen.

Recuperar este contexto de las migraciones procedentes del NCA en tránsito por México es importante para entender el fenómeno de las caravanas, porque están insertas y se configuran dentro de procesos sociales de largo aliento que se han producido no solo en los países de origen y destino, sino de tránsito. En este sentido, cabe destacar que son varias las marchas de migrantes que han recorrido año tras año el territorio mexicano visibilizando la violencia que los centroamericanos sufren en los países de origen y en el tránsito por México; las más destacadas han sido el Viacrucis 
Migrante ${ }^{4}$ y la Caravana de Madres de Migrantes Desaparecidos, ${ }^{5}$ que se consolidaron y adquirieron relevancia política a raíz de la masacre en el municipio de San Fernando, Tamaulipas, en 2010, en la que 72 migrantes —en su mayoría centroamericanosfueron asesinados por el crimen organizado.

Las caravanas de migrantes que llegaron a México en octubre y noviembre de 2018 difieren de la manera tradicional en que han transitado por México los migrantes procedentes del NCA — solos o en grupos pequeños- y guardan similitudes con los viacrucis migrantes, especialmente con el de marzo-abril de ese mismo año. Para entender la naturaleza de las marchas de finales de 2018 deben realizarse una serie de precisiones. Primero, aunque no se trata de un fenómeno atípico desde el punto de vista de las cifras de migrantes, la manera en que transitan juntos en grupos numerosos y de un modo tan visible sí constituye una novedad. Segundo, estas caravanas han superado a booms mediáticos previos en cuanto al fenómeno migratorio centroamericano. ${ }^{6}$ Lo más destacado es que los medios de comunicación han acompañado a los migrantes centroamericanos en gran parte de su recorrido desde Honduras y otros países, visibilizando a los participantes mientras cruzan fronteras y transitando territorios. Tercero, estas caravanas tienen fines más pragmáticos que políticos; como huir de la violencia y buscar una vida vivible (Varela Huerta, 2018) y protegerse los unos a otros. ${ }^{7}$ Cuarto, numerosas organizaciones de la sociedad civil (OSC) y muchos ciudadanos mexicanos y de otros países han apoyado y acompañado a los migrantes a lo largo de todo su recorrido por el país. Quinto, la mayoría de los participantes de las caravanas de finales de 2018 recibieron un trato relativamente menos represivo por las autoridades mexicanas - que los migrantes en tales marchas junto con sus defensores lograron en su "lucha" con aquellas, en la frontera sur de México y sus primeros pasos por el país, reivindicando la legitimidad de sus pretensiones migratorias- que el ofrecido en

\footnotetext{
${ }^{4}$ Los viacrucis migrantes son manifestaciones político-religiosas integradas por migrantes y defensores de los derechos humanos de los migrantes que bajo diferentes lemas hicieron diversos recorridos por México siguiendo las rutas migrantes, realizando protestas y denuncias (Vargas Carrasco, 2018; París Pombo, 2018b, 25 de octubre), alcanzando cierta presencia en los mass-media nacionales e incluso internacionales. El hecho de que muchos de los migrantes participantes en los viacrucis no dispusieran de los documentos exigidos por las leyes mexicanas fue motivo de disputas con las autoridades mexicanas. El trato que estas últimas dieron a estas marchas, en cuanto a la situación irregular de sus integrantes, se puede catalogar de ambiguo y contradictorio, oscilando entre dos extremos: la permisividad (o incluso, el apoyo) y la represión.

${ }^{5}$ Se trata de una "iniciativa transnacional que desde hace más de una década se dedica a buscar a los hijos migrantes desaparecidos en su ruta por México hacia Estados Unidos" (Varela Huerta, 2016, p. 38).

${ }^{6}$ La repercusión mediática de las caravanas de migrantes fue resultado en gran medida de los tuits del presidente de Estados Unidos, Donald Trump. En un primer mensaje en Twitter, Trump "informó" a los mandatarios hondureños de la retirada de ayudas económicas si no detenían la caravana. Las amenazas pronto se extendieron a El Salvador, Guatemala y México.

${ }^{7}$ Esto no quiere decir que esta marcha no tenga diversas lecturas en clave política: i) Al igual que sus antecesoras, estas caravanas han realizado diversas protestas y reclamaciones. ii) El hecho de que miles de migrantes decidan marchar juntos y recorrer territorios y fronteras con y sin autorización de los estados debe ser objeto de análisis desde diferentes campos de estudio de la ciencia política. iii) Las caravanas fueron politizadas por dirigentes de Honduras, México y Estados Unidos.
} 
décadas anteriores a los migrantes procedentes del NCA. ${ }^{8}$ En cualquier caso, las acciones gubernamentales fueron contradictorias, ambiguas y, como es habitual, difíciles de auditar. Sexto, al mismo tiempo que las caravanas marchaban atrayendo casi todos los reflectores, muchos migrantes siguen viajando individualmente y en grupos mucho menos amplios que las caravanas, empleando coyotes. Séptimo, conforme las marchas fueron avanzando hacia el norte, sus participantes tuvieron acceso a oportunidades, $y$ afrontaron una serie de desafíos, que pusieron a prueba su capacidad para desplegar estrategias que les conduzcan al logro de sus metas migratorias ya sea en el corto, medio o largo plazo.

\section{Estrategias en tránsito}

A continuación, se presenta un marco analítico compuesto de cinco tipos de estrategias que a su vez están atravesadas por tres dimensiones transversales: $a$. El género, $b$. Los recursos económicos que tienen y $c$. La información de que disponen. Las estrategias, que no son excluyentes entre sí, fueron escogidas tanto por ser las más destacadas en la literatura académica como por adecuarse al caso de las caravanas de migrantes. Cabe mencionar que ninguna de ellas es plenamente infalible contra todos los riesgos que se presentan a lo largo de las rutas migratorias (Yee Quintero \& Torre Cantalapiedra, 2016; Nájera Aguirre, 2016).

\section{La elección de rutas y medios de transporte}

Los migrantes escogen sus rutas teniendo en cuenta factores como los puntos de mayor vigilancia de las autoridades — tanto las mexicanas como las estadounidenses-, la seguridad — primordialmente, evitar el crimen organizado—, los medios de transporte empleados, las redes de apoyo, la distancia recorrida y costo económico/recursos de que disponen (Díaz Prieto y Khuner, 2014; París Pombo, 2016, 2017). A la estrategia de elección de la ruta principal a seguir, cabe añadir que los migrantes tienden a hacer rodeos a lo largo de las rutas escogidas para poder evitar ciertos peligros que son capaces de prever con la información que poseen (González Arias \& Aikin Araluce, 2015; Yee Quintero \& Torre Cantalapiedra, 2016).

Intrínsecamente ligada a la elección de las rutas está la elección de medios de transporte. Los migrantes hacen uso de diferentes transportes en función de sus posibilidades económicas y si poseen algún tipo de documentación para cruzar por el territorio mexicano - aunque no dispongan de documentos para entrar de forma

\footnotetext{
${ }^{8}$ Entre otras: $i$ ) en general, hubo permisividad/inacción respecto al tránsito irregular de la mayoría de los integrantes de las caravanas; ii) se han habilitado espacios, albergues provisionales, para que puedan pernoctar y residir temporalmente; iii) se han ofrecido una serie de oportunidades especiales para quedarse en el país - véase, por ejemplo, el Plan "Estás en tu casa"-; iv) se les concedió TVRH, entre otras. Otras medidas, incluidas algunas de las anteriores, han sido ampliamente criticadas por ser consideradas en contra de los migrantes y a favor de la contención.
} 
regular en Estados Unidos. ${ }^{9}$ Los que no disponen de dinero se ven orillados a ir a pie durante mayores distancias y a emplear los trenes de carga para transportarse (París Pombo, 2017).

\section{Acompañamiento}

El acompañamiento a lo largo del camino puede constituirse en una táctica estratégica fundamental en términos de recursos materiales — dinero, alimentos, otros-, información —especialmente, orientación espacial y saberes sobre el viaje-, apoyo emocional y la protección que puede ofrecer el acompañante (Villanueva Domínguez, 2012; Parrini Roses \& Flores Pérez, 2018). Así los migrantes pueden salir con familiares, amigos y/o conocidos, o posteriormente juntarse con otras personas.

Durante el camino, pueden encontrarse nuevos compañeros de viaje, tanto si se viaja solo como en grupo. Para muchos, estos contactos son esenciales en el desarrollo de sus viajes, algunos se muestran cautelosos y selectivos para decidir con quienes se juntan (Villanueva Domínguez, 2012), porque una mala elección puede conducir a situaciones de abuso y agresión (Willers, 2016).

Las mujeres han tenido una mayor necesidad de acudir a las estrategias de acompañamiento por sus condiciones de especial vulnerabilidad en el tránsito. Ellas buscan la protección de los varones para afrontar los peligros del camino, pero estos a su vez pueden convertirse en sus agresores (Villanueva Domínguez, 2012; Willers, 2016).

En una investigación sobre migrantes hondureños en tránsito por México que viajan sin coyote y haciendo uso de la red de albergues, encuentran que para evitar mejor los peligros relacionados con la delincuencia y con las autoridades mexicanas, algunos hombres que cuentan con recursos económicos suficientes y experiencia migratoria prefieren viajar solos (Yee Quintero \& Torre Cantalapiedra, 2016).

\section{Obtener algún tipo de documento migratorio}

Son muy pocos los migrantes centroamericanos que obtienen una visa para emigrar a Estados Unidos (París Pombo, 2017), por lo que un creciente número de ellos solicitan asilo y tarjeta de visitante por razones humanitarias (TVRH) en México para obtener documentos que les permitan movilizarse libremente por el país sin ser detenidos por las autoridades (París Pombo, 2018a).

De igual forma, aunque son excluidos de las vías legales "habituales" para internarse en Estados Unidos, existe la posibilidad de solicitar asilo o participar en otros tipos de programas que permiten el acceso al territorio estadounidense temporal o permanentemente. La administración de Trump considera que los solicitantes de asilo centroamericanos son invasores oportunistas que se aprovechan de las lagunas del sistema migratorio estadounidense (Department of Homeland Security [DHS], 2018; Averbuch \& Semple, 2018).

${ }^{9}$ Para un repaso a las rutas y medios de transporte que emplean los migrantes véanse, por ejemplo, París Pombo $(2016,2017)$. 
La información para poner en práctica estas estrategias se obtiene por el contacto con otros migrantes, por los datos que les proporcionan albergues (Candiz \& Bélanger, 2018) y osc, entre otros. Los migrantes que siguen este tipo de estrategias deben esperar meses para que les otorguen ciertos documentos - lo cual resulta un serio contratiempo en sus planes migratorios- y sus solicitudes son frecuentemente denegadas.

\section{Apoyarse en la red asistencial: los albergues}

Organizaciones religiosas, osc, organismos internacionales, ciertos actores estatales y grupos de población apoyan a los migrantes en tránsito a lo largo de las rutas migratorias (Aikin \& Anaya Muñoz, 2013; Candiz \& Bélanger, 2018). La materialización más relevante de esta red de apoyo son los albergues y refugios que ayudan a los migrantes con hospedaje, alimentos, servicios médicos, acompañamiento jurídico, información sobre sus derechos en México, recomendaciones de viaje, entre otros.

Aprovechar estos recursos institucionales como los albergues constituye una estrategia en tránsito básica para miles de migrantes procedentes del NCA que recorren los caminos con muy bajos recursos, especialmente los hondureños (Silva Hernández, 2015; Yee Quintero \& Torre Cantalapiedra, 2016). De acuerdo con Díaz Prieto y Khuner (2014), las mujeres tienen una menor propensión a quedarse en albergues, entre otras razones, porque buscan otras alternativas de alojamiento económico que las hagan sentirse más seguras.

\section{Acudir al servicio de coyotaje ${ }^{10}$}

Pese a la imagen negativa que ofrecen los medios de comunicación y las autoridades gubernamentales de la actividad de coyotaje, ${ }^{11}$ Spener (2008) la considera una estrategia de supervivencia muy buscada por los migrantes para lograr el cruce de fronteras. Las cifras oficiales muestran que la contratación de coyotes es una estrategia en tránsito plenamente extendida entre los centroamericanos para atravesar fronteras y territorios de un modo "irregular" (Díaz Prieto \& Khuner, 2014, París Pombo, 2017).

A diferencia de las otras estrategias mencionadas, que podríamos llamar "básicas", en este caso acudir a coyotes implica dejar en manos ajenas varias decisiones en cuanto a la elección de rutas y medios de transporte, así como el acompañamiento de otras personas migrantes - al menos en las partes del recorrido en las que se hace uso de sus servicios. Para desplegar esta estrategia, los migrantes buscan, de preferencia, guías/

\footnotetext{
${ }^{10} \mathrm{El}$ coyotaje es una actividad sancionada por el estado realizada por los coyotes, polleros o traficantes de migrantes, que son personas que ayudan a migrantes a cruzar una frontera o territorio de manera irregular a cambio de una cierta cantidad de dinero (Torre Cantalapiedra, 2018).

${ }^{11}$ En años recientes, los medios de comunicación han caracterizado al coyotaje de la migración centroamericana por México tras la recuperación acrítica de voces de actores estatales, como una actividad ilícita y lucrativa que recurre al engaño para aprovecharse de los migrantes, que genera situaciones de crisis migratoria y que está en manos del crimen organizado (Torre Cantalapiedra, 2018).
} 
coyotes de confianza - aquellos que cumplen con lo acordado y gozan de buena reputación- para lo que deben lograr los recursos económicos necesarios.

\section{Análisis de las estrategias de participantes en caravanas}

Entre noviembre de 2018 y enero de 2019 , se realizaron 47 entrevistas ${ }^{12}$ a migrantes procedentes del NCA en albergues provisionales en Tijuana, Baja California. ${ }^{13}$ Esto permitió recuperar las experiencias migratorias de quienes prolongaron su participación con el grueso de la caravana hasta la frontera estadounidense y a través de sus relatos analizar las estrategias migratorias en tránsito. ${ }^{14}$ Se entrevistó a 35 migrantes hondureños, 9 salvadoreños, 2 guatemaltecos y 1 nicaragüense; de los cuales, 9 eran mujeres en edades comprendidas entre los 22 y 52 años ( 4 partieron solas y 5 con sus esposos e hijos), y 38 varones de entre los 18 y 63 años (17 partieron solos y 21 con al menos un familiar, amigo o conocido).

La mayoría de los entrevistados pertenecían a categorías laborales asociadas a bajas remuneraciones (trabajadores en agricultura, trabajadores en servicios, artesanos y trabajadores manuales no calificados) que se encontraban en circunstancias económicas precarias en sus países de origen. Por consiguiente, emprendieron el viaje al Norte con pocos recursos monetarios (menos del equivalente a 4000 pesos mexicanos), o incluso, sin ningún fondo. A excepción de dos personas entrevistadas cuyo plan inicial era quedarse en México, la primera intención de los entrevistados era llegar a Estados Unidos.

Para captar el carácter dinámico de la participación en la caravana, el análisis de las estrategias desplegadas por los migrantes entrevistados se realiza teniendo en cuenta diferentes etapas de su recorrido hacia el Norte.

\footnotetext{
${ }^{12}$ El número de entrevistas se determinó por el criterio de saturación; esto es, se interrogó a nuevos entrevistados hasta que dejaron de ofrecer información distinta a la descrita por los anteriores para el entendimiento de las estrategias migratorias en tránsito.

${ }^{13}$ Las entrevistas en Tijuana fueron realizadas principalmente en las inmediaciones de los lugares en que se albergaban los migrantes de manera temporal y precaria: 13 en la Unidad Deportiva Benito Juárez en el centro de la ciudad, incluida la calle aledaña donde colocaron decenas de tiendas de campaña, y 32 en un espacio destinado a conciertos y otros eventos, conocido como "El Barretal". Adicionalmente, una entrevista fue conducida frente a la garita de "El Chaparral" y otra ante las oficinas del INM.

${ }^{14}$ Los que llegaron hasta Tijuana son solo una parte de todos aquellos que en alguna ocasión participaron en la caravana. "Atrás" quedaron quienes regresaron a sus países en cualquier punto del camino, quienes fueron deportados por las autoridades mexicanas, quienes solicitaron refugio en Chiapas u otro estado de México, quienes aprovecharon alguna oportunidad en México para quedarse y trabajar, quienes murieron en el camino, quienes se separaron del grueso de la caravana para seguir otras rutas para acceder a Estados Unidos de manera indocumentada o pedir asilo y quienes pretendían alcanzar otros destinos dentro del territorio mexicano.
} 


\section{Unirse a la caravana: el acompañamiento y la falta de recursos}

Tamara (22 años, hondureña, ayudante de cocina $)^{15}$ y su marido llevaban meses queriendo emprender el camino hacia Estados Unidos debido a su situación económica precaria en Honduras y sabedores de las posibilidades laborales que encontrarían en territorio estadounidense -él fue deportado de Estados Unidos, donde actualmente residen sus cuatro hermanos. En la caravana vieron su "única oportunidad" de viajar al Norte, "nos queríamos venir, pero no sabíamos cómo, porque no teníamos dinero para pagar un coyote, y venir solos da miedo [...] con la caravana, como es bastante gente, nos cuidamos unos a otros". En la vivencia de esta pareja se manifiestan dos atractivos fundamentales y más evidentes de las caravanas: el acompañamiento masivo para el viaje — con lo que eso implica en términos de seguridad, apoyo emocional y material e información-, y el que están abiertas a personas de muy bajos recursos. Esta fuerza atractiva no solo fue para las personas que se hallaban en sus países de origen, sino también para muchas personas que se encontraban en tránsito.

La mayoría de los entrevistados tiene la percepción de que viajar con la caravana es relativamente seguro, sobre todo en cuanto a protegerse de los grupos criminales: "cuando se va solo más fácil pueden agarrar a uno y llevarlo para cualquier lado" (Ignacio, hondureño, 25 años, ayudante de albañil). Sin embargo, esto no supone que consideren ir en estas marchas exentos de riesgos y dificultades. Muchos migrantes buscan la compañía de familiares, amigos y conocidos para viajar con la caravana. Una encuesta realizada a integrantes de la caravana en uno de los albergues provisionales en Tijuana apunta a que las mujeres son mucho más propensas a viajar acompañadas que los hombres; mientras que más de la mitad de los entrevistados varones emprendió el viaje solo, la mayoría de las mujeres viajaba con algún familiar (El Colef, 2018). Aunque esto no quiere decir que todas ellas lo hicieran por protección, para empezar porque en algunos casos sus acompañantes son sus hijas e hijos de corta edad.

Viajar con las caravanas fue accesible incluso para personas en situación de pobreza, porque no exigía disponer de muchos recursos económicos para desplazarse -ir a pie y mayormente en aventones/jalones - y pernoctar - albergues, carpas y otros locales techados que pusieron a su disposición en el camino o si no al raso- $;{ }^{16}$ y por la solidaridad de OSC, de ciudadanos y de los propios participantes.

Varios de los migrantes entrevistados consideran esta forma de viajar como su única opción ante la imposibilidad de afrontar los elevados costes de acudir a los coyotes:

\footnotetext{
${ }^{15}$ Se utilizan nombres ficticios para preservar la confidencialidad. Los datos recuperados para cada entrevistado son: nacionalidad, edad al momento de la entrevista y última ocupación en sus países de origen.

${ }^{16}$ Para muchos de los entrevistados, las largas caminatas fueron lo más difícil del camino, quienes vieron cómo otros desistieron por agotamiento físico en varios puntos del camino. Aquellos migrantes que contaban con recursos podían alternativamente emplear autobuses y otros medios de transporte. Varios migrantes gastaron sus ahorros en transportes que les permitieran alcanzar a alguna de las caravanas en diversos puntos del recorrido. En territorio mexicano, además de los aventones que lograron durante días, cabe destacar que desde Guadalajara (Jalisco) hasta Tijuana y Mexicali (Baja California) tuvieron el apoyo de autoridades estatales y osc para recorrer en autobús alrededor de 2000 kilómetros.
} 
Una noche llegué de trabajar, yo me acuerdo, un sábado, y me puse a ver noticias en la televisión y me fijé que ese día salían de San Pedro Sula a las 6 de la mañana. Pues yo me dije "aquí está mi oportunidad", porque como no tengo capacidad para pagar a los mentados coyotes, cobran demasiado (Pedro, hondureño, 42 años, soldador).

A medida que las caravanas avanzaban hacia el Norte, a través de los medios de comunicación, redes sociales y conversaciones, otros potenciales migrantes se enteraban de las vicisitudes de quienes participaban en tales marchas, pero al mismo tiempo, podían observar con mayor nitidez sus ventajas: "Ya que se dio la oportunidad de salir a esta caravana sin gastar gran dineral de venir pagando [coyote], pues decidimos también venir nosotros, a ver si también nosotros conseguimos pasar al otro lado" (Rosa, salvadoreña, 22 años, trabajadora en la agricultura).

Aunque en un número reducido, varios de los entrevistados participantes en las caravanas contaban con el apoyo de familiares o recursos económicos suficientes para sufragar los elevados costes del coyotaje, que contemplaban como una opción a la que recurrir en función de la evolución de las caravanas pues esperaban que los costes de este servicio se abaratasen conforme más se acercaran al destino, Estados Unidos. Francisco (hondureño, 21 años, negocio propio), quien contaba con apoyo económico de sus tíos en California, planeó realizar una parte de viaje con la caravana y ser recogido por su coyote de confianza una vez superada la frontera sur mexicana y parte de su territorio.

\section{¿Derribando las fronteras oficiales? ¿Protegiéndose contra la delincuencia?}

Los relatos de los migrantes respecto a su paso por la frontera México-Guatemala y sobre el trato que recibieron por las autoridades mexicanas tras cruzarla y en el tránsito por el territorio mexicano son dispares. Lo que es indicativo de que no todas las caravanas, ni todos los participantes en cada una de ellas corrieron la misma suerte. ${ }^{17}$ En cualquier caso, las historias recuperadas de los migrantes, especialmente aquellas de quienes tuvieron experiencias migratorias previas, apuntan hacia que la mayoría de los participantes en las caravanas tuvieron menos percances con la delincuencia y agentes del estado corruptos, y no enfrentaron la misma frontera vertical oficial vigente en épocas anteriores.

La mayor parte de los entrevistados sin experiencia migratoria, aparte de su participación en las caravanas, consideran que las autoridades no dificultaron excesivamente el paso de la marcha en la que viajaban:

El gobierno [mexicano] a veces nos paraba, nos pedían documentos, pero como veníamos con la caravana no se nos puso tan difícil. Yo pensaba que no nos iban a dejar pasar, para cruzar la línea de México. No se nos puso tanto

\footnotetext{
${ }^{17}$ En este sentido, es conveniente recordar que los entrevistados en Tijuana son personas que tuvieron éxito para cruzar las fronteras entre Guatemala y México y que, por tanto, se pierden las experiencias de aquellas personas que fueron detenidas y deportadas por las autoridades, cuyos relatos respecto al actuar de las autoridades mexicanas posiblemente sean más críticos.
} 
de difícil, pero sí batallamos un ratito. [...] Yo pensaba que [...] llegando a México nos iban a regresar pátrás. Se portaron bien (Federico, 58 años, carpintero).

Quienes tienen experiencia migratoria pueden poner en perspectiva sus vivencias actuales en la caravana de migrantes. Roberto (hondureño, 58 años, negocio propio), quien salió de su país natal por amenazas de muerte y para reunirse con esposa e hijos en Estados Unidos, posee una experiencia migratoria en tránsito a finales de la década de 1990:

Cuando me vine de allá [Honduras], me vine caminando, estaba más duro, nosotros veníamos caminando por montes, ;Sufrí! Por eso había dicho yo "que no volvía", pero como aproveché que venía una caravana, nos abrieron el paso. [...] La primera vez que vine yo, los mexicanos nos pedían dinero, los policías, los de la patrulla nos pedían dinero, si no dábamos nos tiraban pátrás, les pagamos, veníamos como cinco, y entre todos los que veníamos juntábamos para el que no tenía. [...] Este viaje [con la caravana] ha sido más tranquilo, más relajado, porque uno viene con toda la gente, los policías nos vienen dejando la entrada libre, todo tranquilo (hondureño, 58 años, negocio propio).

En los últimos años, la frontera vertical oficial mexicana ha supuesto serias dificultades para que los migrantes en tránsito irregular lleguen a la frontera México-Estados Unidos. Esta realidad dejó su huella en la experiencia de Guillermo (salvadoreño, 30 años, mesero), quien salió de su país de origen en marzo de 2018 huyendo de la violencia de las pandillas, en forma de dos deportaciones por las autoridades migratorias mexicanas. Tras sendos intentos infructuosos de cruzar el territorio mexicano, solicitó refugio ante la Comisión Mexicana de Ayuda a Refugiados (Comar), para obtener documentos que le permitiesen el libre tránsito por México. En cuanto obtuvo una TVRH, viajó en autobús desde Tapachula a la Ciudad de México, para unirse a la caravana en su tránsito hacia Tijuana.

Contrastantemente, algunos migrantes entrevistados que se unieron a las marchas en su tramo final desde Mexicali, y/o se alojaron en los mismos albergues provisionales en la ciudad de Tijuana que los participantes en las caravanas, tuvieron que lidiar con la frontera vertical. Puesto que cruzaron de Guatemala a México y/o parte del trayecto por México en solitario o grupos pequeños y sin seguir los cauces establecidos por las autoridades, reportaron tanto haber sido perseguidos por los agentes de migración en el sur —es más, algunos de sus compañeros de viaje fueron detenidos y deportados-, como haber enfrentado asaltos en los trenes en los que se desplazaban.

\section{Siguiendo la ruta trazada por las caravanas hacia Tijuana}

Seguir a las caravanas supone que los migrantes no deciden individualmente las rutas por las que van a transitar hacia Estados Unidos y a qué región fronteriza se van a aproximar. La primera y subsiguientes caravanas se dirigieron hacia la ciudad de Tijuana —el mismo destino que los migrantes haitianos en 2016 (Yee Quintero, 2017). El grueso de los participantes en las caravanas de finales de 2018 se dirigió a esta ciudad. 
Existieron varios incentivos para mantenerse con la caravana en su curso hacia el Norte: $i$ ) tratarse de la ruta más segura en términos de una menor presencia del crimen organizado; ii) que transitar sin la caravana podría exponer a la detención y la subsiguiente deportación —estas dos circunstancias indican que la frontera vertical, tanto extraoficial como oficial, sigue configurando de manera considerable las decisiones que toman los migrantes-; iii) por tanto, seguir a la mayoría ofrecía ventajas en términos de protección contra el Estado mexicano y los criminales; $i v$ ) la idea, poco realista, de que se les permitiría el paso a Estados Unidos de una forma excepcional; $v$ ) la ausencia de recursos económicos para ir por otras rutas; vi) el apoyo con que contaban por osc —incluida la facilitación de medios de transporte-; y, vii) la falta de información sobre la realidad fronteriza en cuanto a las posibilidades de cruce legal e "irregular", entre otros. Así muchos migrantes entrevistados se "dejaron llevar" por la caravana.

Algunos mostraron cierta frustración y/o arrepentimiento de haber seguido a la caravana hasta dicha ciudad, porque su intención de cruzar de manera irregular se ve dificultada en esa franja fronteriza. Carlos (hondureño, 42 años, desempleado) siguió a la caravana hasta Tijuana por falta de recursos, pero señalaba su descontento porque esperaba que la caravana se hubiera ido por Reynosa u otra frontera donde sus opciones de lograr el cruce indocumentado fueran mayores. Con dos deportaciones en el año 2010 desde la frontera de Estados Unidos consideró que sus posibilidades de ganar la "pelea del asilo" eran escasas.

De acuerdo con los entrevistados, una proporción considerable de los migrantes se escindieron de la caravana, en diferentes puntos de la geografía mexicana, para seguir sus propios planes migratorios "hacia otras fronteras" —otras partes de la frontera entre México y Estados Unidos. Esta posibilidad de irse por cuenta propia parece estar relacionada con poseer recursos económicos. Entre otras, permite acceder al servicio del coyotaje: "me encontré otro amigo, él sí se fue por allá [Reynosa], le pagaron quien lo cruzara. Él ya está allá [Estados Unidos], y me escribe y me dice 'yo ya estoy acá”" (Esteban, hondureño, 27 años, varios empleos).

\section{¿Atrapados en Tijuana? Asilo, coyotaje y cruce indocumentado}

A comienzos de diciembre de 2018, según fuentes periodísticas, más de 6200 migrantes centroamericanos habían llegado a Tijuana (Martínez, 2018) siguiendo las rutas trazadas por las caravanas de migrantes. A pesar de los obstáculos que encuentran en esta ciudad para el objetivo de alcanzar el territorio estadounidense -muros, trabas burocráticas, políticas antiinmigrantes y en contra de los solicitantes de asilo, etcétera—, como la desinformación — gran cantidad de rumores- y el desconocimiento de los sistemas legales de México y Estados Unidos para solicitar protección internacional, todos los migrantes tienen a disposición múltiples opciones 
de movilidad y permanencia, ${ }^{18}$ y despliegan decisiones y acciones estratégicas de diversa índole. A continuación, nos centramos en aquellos que persistieron en su intención de llegar a Estados Unidos.

En la región fronteriza de Tijuana se han erigido desde la década de 1990 diferentes tipos de barreras para impedir el cruce irregular. Por lo tanto, una de las pocas opciones factibles para pasar al territorio estadounidense desde tal ciudad es a través de las solicitudes de asilo. ${ }^{19}$ Para acceder a iniciar el trámite, la mayoría de los migrantes entrevistados se apuntaron en una lista gestionada desde 2016 por los propios migrantes, que supone esperar ${ }^{20}$ meses para tener la posibilidad de exponer su caso (Semple, 2018). ${ }^{21}$ Enfrentaron lo que se conoce como metering, política estadounidense que consiste en reducir arbitrariamente el número de personas que pueden iniciar su trámite diariamente en cada puerto de entrada oficial a Estados Unidos y que dilata el proceso de manera artificial, estrategia que pretende hacer desistir a los actuales solicitantes y disuadir a otros para que no soliciten asilo en el futuro.

Una gran parte de los migrantes entrevistados apuntados en la lista no tenían planes de pedir asilo en Estados Unidos cuando iniciaron el viaje, y la gran mayoría desconocen casi por completo el complejo funcionamiento del cada vez más restrictivo sistema de asilo político en Estados Unidos - por más que varias osc se esforzaron previamente por proporcionarles orientación legal al respecto. Las entrevistas apuntan a que los migrantes, ante una situación donde la toma de decisiones se torna muy difícil debido a la desinformación y a las incertidumbres sobre el proceso, para decantarse sobre si solicitar asilo o no, analizan las acciones de otras personas que forman parte de sus redes de familiares, amigos y conocidos y siguen una estrategia de imitación de aquellas que fueron exitosas, pero sin ninguna intención de sacar provecho de manera dolosa de un sistema jurídico que desconocen.

En ese sentido se puede traer a colación el relato de Oswaldo (hondureño, 38 años, albañil), quien busca cruzar a Estados Unidos con su esposa e hijastro. Él fue deportado, por lo que desea cruzar de manera indocumentada, pero quiere que su esposa y su hijo accedan mediante la petición de asilo. Basándose casi exclusivamente en la experiencia de otros familiares, considera que es mejor que lo soliciten en "otra frontera" y no en Tijuana:

\footnotetext{
${ }^{18}$ Los participantes en la caravana en Tijuana pueden optar por: 1) seguir intentando acceder a Estados Unidos, ya sea mediante el asilo o alguna forma de cruce indocumentado; 2) quedarse en Tijuana temporal o permanentemente; 3) migrar a otro lugar dentro de México; 4) buscar otro país de destino diferente de México o Estados Unidos (véase, por ejemplo, Canadá); y, 5) retornar a sus países de origen mediante los programas de repatriación gubernamentales o los apoyados por organismos internacionales.

${ }^{19} \mathrm{Al}$ igual que los migrantes haitianos y otros migrantes internacionales y nacionales hicieron en años anteriores (Yee Quintero, 2017).

${ }^{20}$ Esta espera no debe entenderse como un periodo donde los migrantes permanecen pasivos, al contrario, los participantes de la caravana utilizan este tiempo para generar recursos de diverso tipo (económicos, documentos migratorios, entre otros).

${ }^{21}$ La otra manera para acceder a solicitar asilo ha sido saltar al otro lado de las bardas fronterizas y ser detenidos por las autoridades estadounidenses. Esta opción, "sin demora", implica varios riesgos: enfrentarse a las autoridades estadounidenses y mexicanas - quienes desincentivan estos intentos con gases lacrimógenos, los primeros, y con arrestos, los segundos- (Averbuch \& Semple, 2018) o sufrir daños físicos por caídas de gran altura, entre otros.
} 
Por allá, las familias se tiran a migración y migración les deja ir a uno. Ahorita pararon tres sobrinos de ella con el cuñado de ella. [...] La hermana de ella vive en Austin, Texas, y mandó traer los niños con el esposo, y ya están allá. [...] Es lo que vengo buscando yo por allá, tengo miedo que ella se entregue aquí [en Tijuana] a migración y la deporten para atrás. Por allá no le van a hacer eso, lo tengo comprobado que no (Oswaldo, hondureño, 38 años, albañil).

El mayor problema es cuando las informaciones son contradictorias y no existe forma alguna de poder determinar cuál es la mejor opción: "Aquí se dicen muchas cosas, algunos dicen que sí [dan asilo], otros dicen que no ... una controversia" (Pedro, hondureño, 42 años, soldador).

Frente a la opción legal del asilo, los migrantes entrevistados en Tijuana consideran la posibilidad de "ir para atrás" y subir por "otras fronteras" para realizar un cruce indocumentado, ya sea por cuenta propia o mediante el uso de coyotes. Sergio (hondureño, 25 años, albañil), quiere trabajar unas semanas en Tijuana para lograr ahorrar el dinero suficiente para "bajarse" en autobús a Monterrey y de ahí probar suerte en el cruce fronterizo. Su meta es reunirse con sus padres y hermanos en Estados Unidos.

Roberto (hondureño, 58 años, negocio propio) tiene un historial migratorio previo en Estados Unidos que le hace temer que le rechacen el proceso de asilo. Dado que dispone de recursos económicos considera al coyotaje su mejor opción para reunirse con sus hijos en territorio estadounidense:

Yo tengo miedo... de entregarme a migración, porque me pueden deportar. Mejor pago un coyote, y así como anduve allá, no van a saber que entré, saben que yo ya salí. Y si entro, no me van a perseguir, porque ellos ya saben que yo ya salí, si yo entro así [con coyote] no hay problema. No me van a andar persiguiendo (Roberto, hondureño, 58 años, negocio propio).

\section{Albergues provisionales y TVRH en Tijuana}

Dos albergues provisionales fueron habilitados en la ciudad de Tijuana, la "Unidad Deportiva Benito Juárez" y "El Barretal". Si bien sus condiciones fueron precarias, los migrantes dispusieron de un espacio para pernoctar, atención médica, dos comidas al día, autobuses para ir a arreglar sus papeles ante el INM —-solicitar las TVRH-, de apoyos de la sociedad civil, ciertas empresas ofrecieron empleos, entre otras. Todas estas opciones permitieron a los participantes de las caravanas mantenerse a la espera de sus trámites de asilo y recabar recursos para ir hacia otros lugares en México o para permanecer en la ciudad.

Las TVRH y los permisos de trabajo que los migrantes solicitaron a las autoridades migratorias en Tijuana les fueron entregados a través de un programa ad hoc, más rápido y con menos complicaciones de las habituales. Estos son para los migrantes un recurso estratégico que puede emplearse de distintas maneras para el logro del objetivo de llegar a Estados Unidos. Sergio (hondureño, 25 años, albañil) trabajará para lograr los recursos que le permitan intentar cruzar a territorio estadounidense por otra zona menos controlada que la de Baja California. Otros la utilizarán, llegado el caso, para 
moverse libremente por el territorio mexicano sin ser detenidos por las autoridades mexicanas. Así, Félix, quien viaja acompañado de su esposa y cuatro hijos, considera la TVRH para regresar a México en caso de que les "falle" el asilo en Estados Unidos:

No estamos seguros, yo traigo una documentación muy grande, pero no estamos seguros. Entonces si me mandaran para Honduras, yo con esa documentación, con ese papel de aquí, yo puedo venirme en bus y no andarme huyéndole a nadie. Puedo venirme, yo creo, que hasta en avión (Félix, hondureño, 63 años, desempleado).

Ya con una TVRH en sus manos, Carlos (hondureño, 42 años, desempleado) optó por regresar a Honduras con su familia mediante un programa de repatriación de la Organización Internacional para las Migraciones. Allí prefiere esperar los tres meses que sus familiares en Estados Unidos le han indicado que tardarán en reunir el dinero para pagar al guía. Su plan es ir desde Honduras hasta Reynosa en sucesivos autobuses - cosa que considera posible gracias a su documento migratorio- y pagar un coyote para el cruce de la frontera México-Estados Unidos por 4000 dólares, la mitad de lo que le cobrarían si el servicio de coyotaje fuera para llevarle a Estados Unidos desde su comunidad de origen.

\section{A manera de conclusión, una nueva estrategia migratoria}

Nuestro análisis está enfocado en las acciones y estrategias individuales de los migrantes y sus familias. ${ }^{22}$ Desde este punto de vista, la participación en caravanas de migrantes puede entenderse como una nueva estrategia de supervivencia de los migrantes para afrontar el tránsito migratorio de manera más segura gracias al acompañamiento masivo, entendido como una poderosa fuente de protección, información y ayuda materia e inmaterial, y que no excluye a las personas de bajos o muy bajos recursos.

Tras adentrarse la primera caravana migrante en territorio mexicano se pudo observar una serie de ventajas y oportunidades de participar en la misma, que se hicieron tangibles a medida que avanzaron por el territorio nacional. Por un lado, las autoridades mexicanas dieron a la caravana un trato diferente al que se ha dado a los migrantes centroamericanos en tránsito durante décadas: cierta "permisividad"/ inacción respecto al tránsito irregular, otorgamiento rápido de TVRH, entre otras.

Por otro lado, recibieron el apoyo de osc y de particulares. Cuando el gran volumen de participantes en las caravanas de migrantes no tuvo cabida en albergues instituidos a lo largo de las rutas migratorias, los apoyos que típicamente se encuentran en estos recintos fueron trasladados a los lugares en que esperaban y pernoctaban los participantes de las caravanas; entre ellos, los improvisados albergues provisionales.

Aunque de un modo distinto al coyotaje, participar en caravanas también supone ceder a otros - en este caso a la colectividad— la toma de ciertas decisiones estratégicas. Ir en caravana supone adecuarse a ciertas rutas, tiempos, medios de transporte (ir a pie, aventones, autobuses) y formas de pernoctar. En este sentido, la elección de Tijuana como destino por la primera y subsiguientes caravanas fue un contratiempo

\footnotetext{
${ }^{22}$ Sin menoscabo de la importancia de futuros análisis sobre las caravanas de migrantes desde la perspectiva de la acción colectiva.
} 
para aquellos quienes, por diversas razones, no consideraban solicitar asilo y no se apartaron antes de las mismas. No siempre se puede reconciliar la meta migratoria individual con participar en las marchas.

Las formas tradicionales de cruzar fronteras y el territorio mexicano se entremezclan con la participación en las caravanas. Quienes tienen recursos -o en su defecto, la capacidad de apartarse de las marchas- combinan estrategias de ir con caravana e ir por otras rutas ya sea solos o pagando servicios de coyotaje.

Todos los participantes en las caravanas migrantes han tenido que afrontar solos la última frontera, que se extiende por más de tres mil kilómetros entre México y Estados Unidos. Así los entrevistados que solicitan asilo hacen frente a un sistema cada vez más restrictivo con el anhelo de alcanzar una calidad de vida mejor en territorio estadounidense, en muchas ocasiones siguiendo una estrategia de imitación de las actuaciones exitosas de familiares, amigos y conocidos.

Las TVRH resultan un recurso estratégico fundamental para los migrantes que no cejan en su empeño de ir a Estados Unidos, tanto para obtener el monto necesario para sufragar los altos costes de los servicios de los coyotes como para adentrarse y moverse libremente por el territorio mexicano. Futuras investigaciones deberán analizar cómo las TVHR favorecen los procesos de integración de quienes desean establecerse en México. De igual manera, examinar en qué proporción el incremento de las solicitudes de refugio - y de TVRH - corresponde a una estrategia de los migrantes para transitar libremente por México y no a una verdadera intención de permanecer.

La participación en las caravanas pone de manifiesto que los migrantes, incluso quienes tienen bajos recursos, son capaces de generar estrategias migratorias en tránsito para el logro de sus objetivos migratorios; pero esto no quiere decir que esté exento de dificultades, puesto que cruzar fronteras erigidas en su contra — batallar con las mismas-, supone desafíos constantes que los participantes afrontan en función de sus conocimientos, actitudes y recursos económicos. Por otro lado, futuras investigaciones deberán analizar con mayor detenimiento las experiencias y estrategias de las caravanas como colectivo de migrantes acompañado y apoyado por los defensores: en cuanto a la elección de rutas, a la hora de lograr medios de transporte, lugares para pernoctar, enfrentar a las autoridades de diferentes países, entre otros. En este sentido, los estudios organizacionales y sobre movimientos sociales tienen mucho que aportar al análisis de este fenómeno migratorio.

En este trabajo nos hemos referido exclusivamente a las caravanas que llegaron a finales de 2018, las que tuvieron que batallar con las autoridades mexicanas para transitar por el país. Sin embargo, este no es el trato que deparó a las siguientes marchas. Mejor recibimiento tuvo la caravana de enero de 2019 a la que el gobierno mexicano atendió con "puertas abiertas" y con la entrega generalizada de TVHR, documento que permite tanto residir y trabajar en México durante un año como transitar libremente por el país. En contraste, la inmunidad que tuvieron las caravanas a la regla general con la que se atendía a la población procedente del NCA — la detención y la deportación, cuya única alternativa es solicitar refugio en México— terminó a inicios de 2019. Desde febrero de dicho año hasta la actualidad, cada caravana llegada a México, o generada en el país, ha sido sistemáticamente desmantelada — sus integrantes mayormente detenidos y deportados o, en su caso, "confinados" a residir y trabajar en la región sur del país. Pese a ello, en marzo de 2020 todavía se seguían convocando caravanas en Honduras, ya que las necesidades de huir de quienes cuentan con menos recursos y de protegerse en el camino siguen plenamente vigentes. Esta diversidad de respuestas 
de las autoridades son una oportunidad para que futuras investigaciones analicen las experiencias y estrategias de los participantes en tales caravanas ante políticas migratorias de muy diversa índole.

\section{Agradecimientos}

Agradecemos muy sinceramente a Isabel Cantalapiedra Malaguilla por su inestimable apoyo para la realización de este trabajo. Asimismo, queremos agradecer a los migrantes centroamericanos que nos compartieron generosamente su tiempo y experiencias migratorias.

\section{Referencias}

Alto Comisionado de las Naciones Unidas para los Refugiados. (2016, 16 de marzo). Preguntas frecuentes sobre los términos 'refugiados' y 'migrantes'. https:// www.acnur.org/noticias/noticia/2016/3/5b9007344/preguntas-frecuentes-sobre-los-terminos-refugiados-y-migrantes.html

Aikin, O. \& Anaya Muñoz, A. (2013). Crisis de derechos humanos de las personas migrantes en tránsito por México: redes y presión nacional. Foro Internacional, LIII(211), 143-181.

Averbuch, M. \& Semple, K. (2018, 3 de diciembre). Ha llegado el momento decisivo para los migrantes de la caravana. The New York Times. https://www.nytimes. com/es/2018/12/03/migrantes-caravana-tijuana/

Calva Sánchez, L. E., Castañeda, A., Coubès, M.-L. \& París Pombo, M. D. (2015). Principales resultados de la encuesta sobre agresión y abuso a migrantes (EAAM) devueltos por las autoridades migratorias, 2012. El Colegio de la Frontera Norte. https://www. colef.mx/wp-content/uploads/2015/03/EAAM_19_marzo.pdf

Candiz, G. \& Bélanger, D. (2018). Del tránsito a la espera: el rol de las casas del migrante en México en las trayectorias de los migrantes centroamericanos. Canadian Journal of Latin American and Caribbean Studies, 43(2), 1-21. https:/ / doi.org /10.1080/08263663.2018.1467533

El Colegio de México. (2018). Diccionario del Español de México. El Colegio de México. http://dem.colmex.mx

Díaz Prieto, G. \& Khuner, G. (2014). Un viaje sin rastros. Mujeres migrantes que transitan por México en situación irregular. Consejo Editorial de la LXII legislatura de la Cámara de Diputados/Instituto para las Mujeres en la Migración A. C./4ta. Editores S. A. de C. V. http://unviajesinrastros.imumi.org/wp/wp-content/ uploads/2016/05/un-viaje-sin-rastros.pdf

Department of Homeland Security (DHS). (2018, 20 de diciembre). Secretary Kirstjen M. Nielsen Announces Historic Action to Confront Illegal Immigration. https://www.dhs.gov/news/2018/12/20/secretary-nielsen-announces-historic-action-confront-illegal-immigration 
El Colegio de la Frontera Norte (El Colef). (2018). La caravana de migrantes centroamericanos en Tijuana 2018. Diagnóstico y propuestas de acción. Autor. https:// www.colef.mx/wp-content/uploads/2018/12/EL-COLEF-Reporte-CaravanaMigrante-_-Actualizado.pdf

El Colegio de la Frontera Norte, Secretaría de Gobernación/Unidad de Política Migratoria, Registro e Identidad de Personas, Consejo Nacional de Población, Secretaría de Relaciones Exteriores, Secretaría del Trabajo y Previsión Social, Consejo Nacional para Prevenir la Discriminación y Secretaría de Bienestar. (2019). Encuesta sobre Migración en la Frontera Sur de México, Informe Anual de Resultados 2018. https://www.colef.mx/emif/informes.php

Giorguli-Saucedo, S. E., García-Guerrero, V. M. \& Masferrer, C. (2018). Un sistema migratorio en construcción. Dinámica demográfica y políticas migratorias en América del Norte y el Triángulo Norte de Centroamérica. Centro de Estudios Demográficos, Urbanos y Ambientales/El Colegio de México. https://cedua.colmex.mx/images/_micrositios/amsitm/amsitm-policy-paper_es.pdf

González Arias, A. \& Aikin Araluce, O. (2015). Migración de tránsito por la ruta del occidente de México: actores, riesgos y perfiles de vulnerabilidad. Migración y Desarrollo, 13(24), 81-115.

Jardón Hernández, A. E. (2011). Nuevos escenarios migratorios internacionales y su papel en las estrategias familiares en México. Revista Latinoamericana de Población, 5(9), 71-99. https://doi.org/10.31406/relap2011.v5.i2.n9.4

Jiménez, H. \& Canchola, A. (2018, 6 de diciembre). Reconoce INm que se encuentran 9 471 migrantes centroamericanos en México. El Universal. https://www.eluniversal.com.mx/nacion/seguridad/reconoce-inm-que-se-encuentran-9-mil-471-migrantes-centroamericanos-en-mexico

Martínez, G. (2018, 4 de diciembre). Pierden en Tijuana a más de 3 mil migrantes de la caravana. El Universal. https://www.eluniversal.com.mx/estados/pierden-entijuana-mas-de-3-mil-migrantes-de-la-caravana

Meléndez, J. (2018, 13 de octubre). Caravana migrante hondureña pasará por México con dirección a Eu. El Universal. https:/ /www.eluniversal.com.mx/mundo/caravana-migrante-hondurena-se-acerca-mexico-rumbo-eu

Méroné, S. C. \& Torre Cantalapiedra, E. (2020). Estrategias de familias migrantes haitianas para sus hijos ante las políticas anti-inmigrantes de República Dominicana. Migraciones Internacionales, 11. https://migracionesinternacionales.colef. $\mathrm{mx} /$ index.php/migracionesinternacionales/article/view/1742/1484

Nájera Aguirre, J. N. (2016). El complejo estudio de la actual migración en tránsito por México: Actores, temáticas y circunstancias. Migraciones Internacionales, 8(3), 255-266. https://migracionesinternacionales.colef.mx/index.php/migracionesinternacionales/article/viewFile/622/165

Parrini Roses, R. \& Flores Pérez, E. (2018). El mapa son los otros: narrativa de viaje de migrantes centroamericanos en la frontera sur de México. Íconos. Revista de Ciencias Sociales, (61), 71-90. https://doi.org/10.17141/iconos.61.2018.3013

París Pombo, M. D. (2016). Trayectos peligrosos: inseguridad y movilidad humana en México. Papeles de Población, 22(90), 145-172. https://rppoblacion.uaemex.mx/ article/view/8259 
París Pombo, M. D. (2017). Violencias y migraciones centroamericanas en México. El Colegio de la Frontera Norte, México.

París Pombo, M. D. (2018a). Movilidad y bloqueo de migrantes centroamericanos en México. En F. Boyer, F. Lestage \& M. D. París Pombo. (Coords.), Rutas y pausas de los recorridos migratorios África-América (pp. 40-48), Cuadernos Cemca (Serie Antropología 3). Centro de Estudios Mexicanos y Centroamericanos.

París Pombo, M. D. (2018b, 25 de octubre). Las caravanas de migrantes, su representación política y los derechos humanos de los migrantes. Observatorio de Legislación y Política Migratoria de El Colef. El Colef. http://observatoriocolef. org/?boletin=boletin-de-prensa-las-caravanas-de-migrantessu-representacion-y-los-derechos-humanos-de-los-migrantes

Peláez, D. C. \& París, M. D. (2016). Deportación femenina y separación familiar: experiencias de mexicanas deportadas a Tijuana. En E. Levine, S. Nuñez \& M. Verea (Coords.), Nuevas experiencias de la migración de retorno (pp. 59-80). UNAM/CISAN/ Instituto Matías Romero-SRE.

Pedone, C., Echevarri, M. M. \& Gil Araujo, S. (2014). Entre dos orillas. Cambios en las formas de organización de las familias migrantes latinoamericanas en España en tiempos de crisis global. En M. E. Zavala de Cosió \& V. Rozée Gomez (Coords.), El género en movimiento. Familia y migraciones (pp. 109-138). El Colegio de México.

Rodríguez Chávez, E. (2016). Migración centroamericana en tránsito irregular por México: nuevas cifras y tendencias (Policy Brief Series, Población). canamid.

Rodríguez Gutiérrez, M. \& Torre Cantalapiedra, E. (s. p.). Camino a la reunificación: análisis de las estrategias migratorias de familias mexicanas tras la separación por deportación.

Semple, K. (2018, 3 de diciembre). La lista que controla los destinos de los migrantes en Tijuana. The New York Times. https://www.nytimes.com/es/2018/12/03/migrantes-tijuana-asilo-lista/

Silva Hernández, A. (2015). Estrategias de tránsito de adolescentes centroamericanos independientes: enfrentando la frontera vertical en México. REMHU, Revista Interdisciplinar da Mobilidade Humana, 23(44), 99-117.

Spener, D. (2008). El apartheid global, el coyotaje y el discurso de la migración clandestina: distinciones entre violencia personal, estructural y cultural. Migración y Desarrollo, (10), 127-156. http://www.scielo.org.mx/pdf/myd/n10/n10a6.pdf

Torre Cantalapiedra, E. (2018), Representaciones mediáticas y migración: análisis de discursos periodísticos respecto al coyotaje en la "crisis migratoria" de 2014. Migración y Desarrollo, 16(30), 157-178. https://estudiosdeldesarrollo.mx/migracionydesarrollo/wp-content/uploads/2018/11/7.pdf

Torre Cantalapiedra, E. (2020). Destino y asentamiento en México de los migrantes y refugiados centroamericanos. TRACE. Procesos mexicanos y centroamericanos, (77). http://trace.org.mx/index.php/trace/article/view/726

Torre Cantalapiedra, E. \& Yee Quintero, J. C. (2018). México ¿una frontera vertical? Políticas de control del tránsito migratorio irregular y sus resultados, 20072016. LiminaR. Estudios Sociales y Humanísticos, 16(2), 87-104. https://doi. org/10.29043/liminar.v16i2.599 
Varela Huerta, A. (2016). Luchas migrantes en contextos de tránsito migratorio, el caso del movimiento migrante centroamericano. REMHU-Revista Interdisciplinar da Mobilidade Humana, 24(48), 31-44. https://doi.org/10.1590/198085852503880004803

Varela Huerta, A. (2018, 4 de noviembre). No es una caravana de migrantes, sino un nuevo movimiento social que camina por una vida vivible. eldiario.es. https:// www.eldiario.es/interferencias/Caravana_migrantes_6_832276775.html

Vargas Carrasco, F. J. (2018). El vía crucis del migrante: demandas y membresía. TRACE Procesos Mexicanos y Centroamericanos, (73), 117-133.

Villanueva Domínguez, M. I. (2012). Género y migración: estrategias de mujeres migrantes centroamericanas en tránsito por México. En E. Tuñón Pablos \& M. L. Rojas Wiesner (Coords.), Género y Migración (pp. 93-116). Ecosur/El Colegio de la Frontera Norte/El Colegio de Michoacán, A. C./ciesas.

Willers, S. (2016). Migración y violencia: las experiencias de mujeres migrantes centroamericanas en tránsito por México. Sociológica, 31(89), 163-195. http://www. sociologicamexico.azc.uam.mx/index.php/Sociologica/article/view/1295

Yee Quintero, J. C. (2017). Caracterizando los solicitantes de asilo en Casa del Migrante: El caso de los haitianos en 2016. En Casa del Migrante en Tijuana, A. C., Vidas en vilo. Historias y testimonios de migrantes internacionales. Casa del Migrante en Tijuana, A. C.

Yee Quintero, J. C. \& Torre Cantalapiedra, E. (2016). Lidiando con la frontera vertical: estrategias migratorias de los hondureños en tránsito por México. $R E^{-}$ MHU: Revista Interdisciplinar da Mobilidade Humana, 24(47), 97-114. https://doi. org/10.1590/1980-85852503880004707

Eduardo Torre Cantalapiedra

Español. Doctor en estudios de población por El Colegio de México. Actualmente es Investigador Cátedras Conacyt en el Departamento de Estudios de Población de El Colegio de la Frontera Norte. Pertenece al Sistema Nacional de Investigadores de México (Nivel 1). Sus líneas de investigación son: migración internacional, política migratoria, patrones migratorios y refugio. Publicaciones recientes: Torre Cantalapiedra, E. (2019). Uso de eufemismos en los discursos del Instituto Nacional de Migración sobre la migración en tránsito por México, Andamios, 16(41), 385-412; y Torre Cantalapiedra, E. (2020). Destino y asentamiento en México de los migrantes y refugiados centroamericanos, TRACE, (77), 122-145.

Dulce María Mariscal Nava

Mexicana. Maestra en estudios en migración internacional por El Colegio de la Frontera Norte. Ha participado en distintos proyectos sobre migración en México y Estados Unidos. Forma parte de la Red de Conacyt Migrare. Sus líneas de interés son: migración, educación y salud. Publicación reciente: Mariscal, D. M. \& Torre Cantalapiedra, E. (2018). Cinco elementos clave para entender la (re)inserción laboral de los migrantes retornados en México en el último decenio. Ser-Migrante. Revista de la Organización Internacional de las Migraciones, (59), 24-37. 